\title{
Hepatotoxicity of Bare and Polyethylene Glycol Coated Iron Oxide Nanoparticles and The Protective Role of Virgin Olive Oil in Male Albino Rats Marwa El-Soudy Abd El-Maqsood Shakra ${ }^{1}$, Rawya Mohammed Salah El-Din ${ }^{1}$, Somaya Youssef Mostafa Hamouda ${ }^{1}$, Amira Abdel Raouf Mohammed ${ }^{2}$ and Rehab Abd Allah Abd Al-Rahman ${ }^{3}$. \\ ${ }^{1}$ Forensic Medicine and Clinical Toxicology Department, Faculty of Medicine for Girls, Al-Azhar University, Egypt, ${ }^{2}$ Cell Biology Department, National Research Centre in Dokki, Egypt, ${ }^{3}$ Histology Department, Faculty of Medicine for Girls, AL-Azhar University, Egypt. Corresponding Author: Marwa El-Soudy Abd El-Maqsood Shakra, Tel.:01062265656, E-mail: drm1432@ yahoo.com
}

\begin{abstract}
Background: Iron oxide nanoparticles (IONPs) are widely used in various biomedical applications. Polyethylene glycol (PEG) is most popular coating option, reduce the aggregation problem of uncoated IONPs and lower toxicity. Liver is a target organ to identify adverse effects of IONPs. Virgin olive oil (VOO) has potent antioxidants and hepatoprotective effects. Aim: The present work aimed to study hepatotoxicity of bare and PEG coated IONPs in male albino rats through biochemical and histopathological study and protective effect of VOO.

Materials and Methods: Seventy seven adult male albino rats were divided randomly into 11 groups: control; PEG; VOO; bare IONPs (15 mg/kg b.wt. and $30 \mathrm{mg} / \mathrm{kg}$ b.wt.) with and without VOO and PEG coated IONPs $(15 \mathrm{mg} / \mathrm{kg}$ b.wt. and $30 \mathrm{mg} / \mathrm{kg}$ b.wt.) with and without VOO. All groups received the treatment by oral gavage daily for four weeks and then blood samples and livers were collected for biochemical and histopathological examination.

Results and Conclusion: Bare and PEG coated IONPs significantly increase AST, ALT, ALP and total bilirubin and significantly decrease total protein. Also, all IONPs treated groups showed significant increase in malondialdehyde (MDA) marker of oxidative stress and significant decrease in SOD and CAT activities (antioxidant markers). All these biochemical changes significantly improved in PEG coated IONPs compared to bare IONPs. Histopathological adverse effects were observed in livers of IONPs treated animals. Significant improvement occurred on coadministration of VOO in these disrupted parameters and improved hepatic tissues damage and function.
\end{abstract}

Keywords: Iron oxide nanoparticles, polyethylene glycol, virgin olive oil, hepatotoxicity.

\section{INTRODUCTION}

The International Organization for Standardization defines nanoparticles (NPs) as structures with dimensions of one, two or three dimensions that are within 1 to 100 nanometers. Because of their small size, the properties of nanomaterials may differ from the properties of bulk materials, which exhibit unique chemical, physical, optical and electrical properties ${ }^{(\mathbf{1})}$.

Currently, the most commercially important nanomaterial's (NMs) are simple metal oxides, such as iron oxide $\left(\mathrm{Fe}_{3} \mathrm{O}_{4}, \mathrm{Fe}_{2} \mathrm{O}_{3}\right)$, aluminum oxide $\left(\mathrm{Al}_{2} \mathrm{O}_{3}\right)$, silica dioxide $\left(\mathrm{SiO}_{2}\right)$, titanium dioxide $\left(\mathrm{TiO}_{2}\right)$ and zinc oxide $(\mathrm{ZnO})^{(2)}$.

Iron oxide nanoparticles (IONPs) are applied due to their unique characteristics, such as their small size, surface chemistry and magnetic properties. Iron oxide nanoparticles have been extensively used during the last two decades, due to a variety of applications such as contrast agent in magnetic resonance imaging (MRI) or as carriers of biomolecules for controlled drug delivery and induced hyperthermia for cancer treatments. Polyethylene glycol has been the most popular coating polymer. It stabilizes IONPs by resisting interaction with blood proteins and therefore, reduces opsonization, macrophage uptake and subsequent monophagocytic system clearance of the IONPs ${ }^{(3)}$.

One of the most important toxic effects induced by iron oxide nanoparticles is their ability to cause oxidative stress. The free iron in the form of ferrous ions $\left(\mathrm{Fe}^{2+}\right)$ can react with hydrogen peroxide and oxygen produced by the mitochondria and creates highly reactive hydroxyl radicals and ferric ions $\left(\mathrm{Fe}^{3+}\right)$ via the Fenton reaction. Hydroxyl radicals generated by the free iron could damage DNA, proteins, lipids, and polysaccharides in the cellular structure ${ }^{(4)}$.

More attentions have been paid to the natural antioxidants owing to its protective effects against metals-induced toxicities, especially whenever reactive oxygen species are involved. Among these natural antioxidants is virgin olive oil (VOO) which is the main source of fat in the Mediterranean diet ${ }^{(5)}$.

Virgin olive oil is well recognized for its antioxidant properties, hypotensive, hypoglycemic, cardiovascular, hepatoprotective, antimicrobial and anti-inflammatory effects. Phenols present in the olive oil are potent antioxidants and scavenge free radicals and inhibit low density lipoprotein (LDL) oxidation. Olive oil contains a wide variety of antioxidants such as vitamin $\mathrm{E}$, oleocanthal and carotenoids ${ }^{(6)}$.

In comparison with other organs, the liver is able to accumulate more than $90 \%$ nanoparticles. Activation of Kupffer cells elicits the release of inflammatory mediators and reactive oxygen species and modulates hepatocyte injury ${ }^{(7)}$.

Based on these facts our study was designed to investigate the toxic effects of bare and PEG coated IONPS on the liver of rats and to study the protective effect of VOO on bare and PEG coated IONPS toxicity in adult male Albino rats through biochemical and histological parameters. 


\section{MATERIALS AND METHODS}

\section{(A) Materials}

\section{I- Experimental Animals:}

Seventy seven male Albino rats of uniform strain with body weight about 150 grams, obtained from the Animal's Farm of Helwan, Egypt.

\section{II-Substances used:}

1- Bare iron oxide nanoparticles (IONPs) and polyethylene glycol coated iron oxide nanoparticles (PEG-IONPs) form $(15-30 \mathrm{~nm}$ ) were purchased from Petroleum Researches Institute, Nasr city, Cairo, Egypt.

2- Virgin olive oil (VOO) was purchased from National Research Center, Dokki, Giza, Egypt.

3- Commercial rat's diet was obtained from local market.

\section{III-Biochemical kits:}

The following parameters were done at cell Biology Department of National Research Center in Dokki Giza, Egypt: Liver function markers and antioxidant markers.

All markers were assayed by using commercial kits, which were purchased from Bio diagnostic company.

\section{(B) Methods}

Preparation of materials:

\section{I- Experimental animals:}

\section{- Handling:}

The handling of animals followed the rules for the experimental research ethics approved by Research Ethics Committee at Faculty of Medicine for Girls Al-Azhar University, Cairo, Egypt. The animals were kept in the Animal House at Faculty of Medicine for Girls, Al-Azhar University. They were housed in clean plastic cages with metal covers; their floors were covered by wood flakes, at room temperature and 12 hours light/dark cycle. The animals were subjected to 7 days period of passive preliminaries in order to adapt themselves to their new environment and to ascertain their physical wellbeing.

\section{- Experimental Design:}

After one week of acclimatization, animals were divided into eleven groups each group contained seven rats, All groups received the treatment by oral gavage daily for four weeks as follow:

Group 1 (Control): rats were received normal feeding and distilled water ad libitum.

Group 2 (PEG): rats received PEG (3 g/kg b.wt.) ${ }^{(8)}$. Group 3 (VOO): rats received VOO $(2 \mathrm{ml} / \mathrm{kg} \mathrm{b.wt}$.) (9).

Group 4 (Low dose bare IONPs): rats received bare IONPs (15 mg/kg b.wt.) ${ }^{(10)}$.

Group 5 (High dose bare IONPs): rats received bare IONPs (30 mg/kg b.wt.) ${ }^{(10)}$.
Group 6 (Low dose bare IONPs + VOO): rats received bare IONPs (15 $\mathbf{~ m g / k g ~ b . w t . ) ~}{ }^{(\mathbf{1 0})}$ and were concomitantly given $\operatorname{VOO}(2 \mathrm{ml} / \mathrm{kg} \text { b.wt. })^{(9)}$.

Group 7 (High dose bare IONPs + VOO): rats received bare IONPs $\left(\mathbf{3 0} \mathbf{~ m g / k g ~ b . w t . )}{ }^{(\mathbf{1 0})}\right.$, and were also given $\operatorname{VOO}(2 \mathrm{ml} / \mathbf{k g} \text { b.wt. })^{(9)}$.

Group 8 (Low dose PEG coated IONPs): rats received PEG coated IONPs ( $15 \mathbf{~ m g / k g ~ b . w t . ) ~}{ }^{(\mathbf{1 0})}$.

Group 9 (High dose PEG coated IONPs): rats received PEG coated IONPs (30 $\mathbf{~ m g / k g ~ b . w t . ) ~}{ }^{(\mathbf{1 0})}$.

Group 10 (Low dose PEG coated IONPs + VOO): rats received PEG coated IONPs $(\mathbf{1 5} \mathbf{~ m g / k g ~ b . w t . ~})^{(\mathbf{1 0})}$ and were concomitantly given VOO $(2 \mathrm{ml} / \mathbf{k g ~ b . w t} .)^{\left({ }^{(9)}\right.}$. Group 11 (High dose PEG coated IONPs + VOO): rats received PEG coated IONPs (30 $\mathbf{~ m g / k g ~ b . w t . ) ~}{ }^{(\mathbf{1 0 )}}$, and were concomitantly given $\operatorname{VOO}(2 \mathrm{ml} / \mathbf{k g} \text { b.wt. })^{\left({ }^{(9)}\right.}$.

- Sampling:

At the end of experimental period after 24 hours from the last dose rats were sacrificed after being anaesthetized with diethyl ether by inhalation. 1-Blood samples: Blood samples were collected from the retro-orbital venous plexus before they were sacrificed in sterile separator tubes. The blood samples were centrifuged at $2000 \mathrm{rpm}$ for $15 \mathrm{~min}$, to separate the sera for assessment of liver function markers (ALT, AST, Alkaline phosphatase, total bilirubin and total protein), oxidative stress marker (MDA) and antioxidant markers (\% of inhibition of SOD and CAT).

2- Tissue samples: Liver was excised for histopathological examination.

Biochemical studies:

1) Liver function markers (ALT, AST, alkaline phosphatase, total bilirubin and total protein):

- Quantitative estimation of serum alanine transaminases (ALT) activity: According to International Federation of Clinical Chemistry (IFCC) ${ }^{(11)}$.

- Quantitative estimation of serum aspartate transaminase (AST) activity: According to the IFCC $^{(11)}$.

- Quantitative estimation of serum alkaline phosphatase (ALP): According to Scandinavian Society ${ }^{(12)}$.

- Quantitative estimation of total bilirubin: According to Walter and Gerade ${ }^{(13)}$.

- Quantitative estimation of total protein: according to Gomal et al. ${ }^{(14)}$.

2) Oxidative stress marker:

- Quantitative estimation of serum malondialdehyde (MDA) [the product of lipid peroxidation]: According to Ohkawa et al. ${ }^{(15)}$.

3) Antioxidant markers ( $\%$ of inhibition of superoxide dismutase and catalase): 
- Quantitative estimation of SOD: According to the Nishikimi et al. ${ }^{(16)}$.

- Quantitative estimation of CAT: According to the Aebi ${ }^{(17)}$.

\section{Histopathological studies:}

Liver sections were stained with hematoxylin and eosin stain: as a routine method for studying the general histological structure of liver then examined under light microscope ${ }^{(\mathbf{1 8 )}}$.

Statistical analysis:

Values were presented as mean and standard deviation (SD) values. Data were explored for normality using Kolmogorov-Smirnov test of normality. The results of Kolmogorov-Smirnov test indicated that most of data were normally distributed (parametric data), so one way analysis of variance ANOVA test was used to compare between groups, followed by post hoc test (LSD) for pairwise comparisons. The significance level was set at $p \leq 0.05$. Statistical analysis was performed with SPSS 20 (Statistical Package for Scientific Studies, SPSS, Inc, Chicago, IL, USA) for Windows.

\section{RESULTS}

I- Biochemical results

1) Liver function markers:

There was a statistically significant increase $(p \leq 0.05)$ in serum levels of AST, ALT, ALP and total bilirubin and significant decrease $(p \leq 0.05)$ in serum levels of total proteins in all IONPs treated groups compared to control group in a dose dependent manner, with improvement in PEG coated IONPs treated groups than bare IONPs treated groups. However, Coadministration of VOO showed more improvement ( $\mathrm{p}$ $<0.05$ ) in all liver function markers (Table 1).

Table (1): The effect of sub chronic toxicity of bare and PEG coated iron oxide nanoparticles on the liver function markers in adult male albino rats and the possible protection by virgin olive oil on the studied groups

\begin{tabular}{|c|c|c|c|c|c|c|}
\hline \multirow{2}{*}{\multicolumn{2}{|c|}{$\begin{array}{l}\text { Groups } \\
\text { n=7 rats /group }\end{array}$}} & AST (Iu/l) & ALT (Iu/l) & $\operatorname{ALP}(\mathbf{I u} / \mathbf{l})$ & $\begin{array}{c}\text { Total Bilirubin } \\
(\mathrm{mg} / \mathrm{dl})\end{array}$ & $\begin{array}{c}\text { Total proteins } \\
\text { (g/dl) }\end{array}$ \\
\hline & & Mean \pm SD & Mean \pm SD & Mean \pm SD & Mean \pm SD & Mean \pm SD \\
\hline \multicolumn{2}{|c|}{ Group 1 (Control) } & $49.62 \pm 1.91^{\mathrm{g}}$ & $52.44 \pm 1.77^{\mathrm{g}}$ & $150.41 \pm 0.93^{h}$ & $0.27 \pm 0.01^{\mathrm{ij}}$ & $10.65 \pm 0.64^{a b}$ \\
\hline \multicolumn{2}{|c|}{ Group 2 (PEG) } & $50.59 \pm 1.18^{g}$ & $53.16 \pm 0.91^{g}$ & $151.76 \pm 1.09^{h}$ & $0.28 \pm 0.01^{j}$ & $9.60 \pm 0.54^{c}$ \\
\hline \multicolumn{2}{|c|}{ Group 3 (VOO) } & $48.67 \pm 1.83^{g}$ & $49.57 \pm 1.72^{h}$ & $149.27 \pm 0.93^{h}$ & $0.27 \pm 0.01^{j}$ & $11.13 \pm 0.59^{a}$ \\
\hline \multicolumn{2}{|c|}{$\begin{array}{l}\text { Group } 4 \text { (Low dose bare } \\
\text { IONPs) }\end{array}$} & $\begin{array}{c}61.01 \pm 1.322^{d} \\
\uparrow 23 \%\end{array}$ & $\begin{array}{c}66.72 \pm 1.20^{c} \\
\uparrow 27.2 \%\end{array}$ & $\begin{array}{c}436.58 \pm 11.51^{b} \\
\uparrow 190.3 \%\end{array}$ & $\begin{array}{c}0.54 \pm 0.02^{b} \\
\uparrow 100 \%\end{array}$ & $\begin{array}{l}7.51 \pm 0.57^{\mathrm{e}} \\
\downarrow 29.5 \%\end{array}$ \\
\hline \multicolumn{2}{|c|}{$\begin{array}{l}\text { Group } 5 \text { (High dose bare } \\
\text { IONPs) }\end{array}$} & $\begin{array}{c}70.62 \pm 1.044^{\mathrm{a}} \\
\uparrow 42.3 \%\end{array}$ & $\begin{array}{c}76.35 \pm 1.35^{\mathrm{a}} \\
\uparrow 45.6 \%\end{array}$ & $\begin{array}{c}516.55 \pm 10.33^{\mathrm{a}} \\
\uparrow 243.4 \%\end{array}$ & $\begin{array}{c}0.62 \pm 0.02^{\mathrm{a}} \\
\uparrow 129.6 \% \\
\end{array}$ & $\begin{array}{c}6.50 \pm 0.54^{\mathrm{f}} \\
\downarrow 39 \%\end{array}$ \\
\hline \multicolumn{2}{|c|}{$\begin{array}{l}\text { Group } 6 \text { (Low dose bare } \\
\text { IONPs + VOO) }\end{array}$} & $\begin{array}{c}54.68 \pm 0.80{ }^{\mathrm{e}} \\
\uparrow 10.2 \% \\
\end{array}$ & $\begin{array}{c}57.39 \pm 0.94^{\mathrm{e}} \\
\uparrow 9.4 \%\end{array}$ & $\begin{array}{c}263.68 \pm 10.78^{\mathrm{e}} \\
\uparrow 75.3 \%\end{array}$ & $\begin{array}{c}0.32 \pm 0.02^{\mathrm{f}} \\
\uparrow 18.5 \% \\
\end{array}$ & $\begin{array}{c}9.55 \pm 0.85^{c} \\
\downarrow 10.3 \%\end{array}$ \\
\hline \multicolumn{2}{|c|}{$\begin{array}{l}\text { Group } 7 \text { (High dose bare } \\
\text { IONPs + VOO) }\end{array}$} & $\begin{array}{c}62.92 \pm 0.94^{c} \\
\uparrow 26.8 \%\end{array}$ & $\begin{array}{c}66.79 \pm 1.74^{\mathfrak{c}} \\
\uparrow 27.4 \%\end{array}$ & $\begin{array}{c}365.91 \pm 11.67^{c} \\
\uparrow 143.3 \%\end{array}$ & $\begin{array}{l}0.35 \pm 0.01^{\mathrm{e}} \\
\uparrow 29.6 \%\end{array}$ & $\begin{array}{c}8.92 \pm 0.84^{\text {cd }} \\
\downarrow 16.3 \%\end{array}$ \\
\hline \multicolumn{2}{|c|}{$\begin{array}{l}\text { Group } 8 \text { (Low dose PEG } \\
\text { coated IONPs) }\end{array}$} & $\begin{array}{c}59.91 \pm 1.12{ }^{d} \\
\uparrow 20.7 \%\end{array}$ & $\begin{array}{c}60.54 \pm 1.25^{\mathrm{d}} \\
\uparrow 15.5 \%\end{array}$ & $\begin{array}{c}342.32 \pm 8.04^{\mathrm{d}} \\
\uparrow 127.6 \%\end{array}$ & $\begin{array}{c}0.39 \pm 0.02{ }^{\mathrm{d}} \\
\uparrow 44.5 \%\end{array}$ & $\begin{array}{c}8.92 \pm 0.83^{\text {cd }} \\
\downarrow 16.3 \%\end{array}$ \\
\hline \multicolumn{2}{|c|}{$\begin{array}{l}\text { Group 9(High dose PEG } \\
\text { coated IONPs) }\end{array}$} & $\begin{array}{c}66.73 \pm 1.20^{b} \\
\uparrow 34.5 \%\end{array}$ & $\begin{array}{c}70.80 \pm 1.52^{b} \\
\uparrow 35 \%\end{array}$ & $\begin{array}{c}433.22 \pm 10.20^{b} \\
\uparrow 188 \%\end{array}$ & $\begin{array}{c}0.43 \pm 0.01^{\mathrm{c}} \\
\uparrow 59.3 \%\end{array}$ & $\begin{array}{c}8.64 \pm 0.55^{\mathrm{d}} \\
\downarrow 18.9 \%\end{array}$ \\
\hline \multicolumn{2}{|c|}{$\begin{array}{l}\text { Group } 10 \text { (Low dose } \\
\text { PEG coated IONPs + } \\
\text { VOO) }\end{array}$} & $\begin{array}{c}51.85 \pm 1.23^{\mathrm{f}} \\
\uparrow 4.5 \%\end{array}$ & $\begin{array}{c}54.89 \pm 0.97^{\mathrm{f}} \\
\uparrow 4.7 \%\end{array}$ & $\begin{array}{c}169.86 \pm 8.06^{\mathrm{g}} \\
\uparrow 13 \%\end{array}$ & $\begin{array}{c}0.28 \pm 0.01 h^{i} \\
\uparrow 3.7 \%\end{array}$ & $\begin{array}{c}10.35 \pm 0.57^{b} \\
\downarrow 2.8 \%\end{array}$ \\
\hline \multicolumn{2}{|c|}{$\begin{array}{l}\text { Group 11(High dose } \\
\text { PEG coated IONPs + } \\
\text { VOO) }\end{array}$} & $\begin{array}{c}55.89 \pm 1.01^{\mathrm{e}} \\
\uparrow 12.6 \%\end{array}$ & $\begin{array}{c}59.36 \pm 1.46^{\mathrm{d}} \\
\uparrow 13.2 \%\end{array}$ & $\begin{array}{c}201.08 \pm 10.19^{f} \\
\uparrow 33.7 \%\end{array}$ & $\begin{array}{c}0.30 \pm 0.01 g^{h} \\
\uparrow 11.1 \%\end{array}$ & $\begin{array}{c}9.30 \pm 0.44 c^{d} \\
\downarrow 12.7 \%\end{array}$ \\
\hline \multirow{2}{*}{$\begin{array}{l}\text { One way } \\
\text { ANOVA }\end{array}$} & $\mathbf{F}$ & 224.360 & 256.982 & 1695.795 & 477.321 & 30.312 \\
\hline & P value & $<0.001$ & $<0.001$ & $<0.001$ & $<0.001$ & $<0.001$ \\
\hline
\end{tabular}

$\mathbf{P E G}=$ polyethylene glycol; $\mathbf{V O O}=$ virgin olive oil; $\mathbf{I O N P s}=$ iron oxide nanoparticles; $\mathbf{A S T}=$ aspartate aminotransferase; $\mathbf{A L T}=$ alanine aminotransferase; $\mathbf{A L P}=$ alkaline phosphatase; $\mathrm{n}=$ number; $\mathbf{S} . \mathbf{D}=$ standard deviation; $\%=\%$ change from control group; $\mathbf{L S D}=$ least significant difference. Means with different superscript letters are significantly different at $p<0.05$, whereas means with the same superscript letters are non-significantly different in the same column. 


\section{2) Oxidative stress marker:}

There was a statistically significant increase $(\mathrm{p} \leq 0.05)$ in serum levels of malondialdehyde (MDA) in all IONPs treated groups compared to control group in a dose dependent manner, with improvement in PEG coated IONPs treated groups than bare IONPs treated groups. However, Co-administration of VOO showed more improvement $(\mathrm{p}<0.05)$ in serum levels of MDA (Table 2).

Table (2): The effect of sub chronic toxicity of bare and PEG coated iron oxide nanoparticles on oxidative stress marker (MDA) in adult male albino rats and the possible protection by virgin olive oil on the studied groups

\begin{tabular}{|c|c|c|}
\hline \multirow{2}{*}{\multicolumn{2}{|c|}{$\begin{array}{l}\text { Groups } \\
\text { n=7 rats/group }\end{array}$}} & $\begin{array}{c}\text { Malondialdehyde (MDA) in serum } \\
\text { nmol/ml }\end{array}$ \\
\hline & & Mean \pm SD \\
\hline \multicolumn{2}{|l|}{ Group 1 (Control) } & $6.94 \pm 0.11^{g}$ \\
\hline \multicolumn{2}{|l|}{ Group 2 (PEG) } & $7.08 \pm 0.12^{g}$ \\
\hline \multicolumn{2}{|l|}{ Group 3 (VOO) } & $6.83 \pm 0.16^{g}$ \\
\hline \multicolumn{2}{|c|}{ Group 4 (Low dose bare IONPs) } & $\begin{array}{l}12.09 \pm 0.56^{b} \\
\uparrow 74.2 \%\end{array}$ \\
\hline \multicolumn{2}{|c|}{ Group 5 (High dose bare IONPs) } & $\begin{array}{l}14.61 \pm 0.43^{\mathrm{a}} \\
\uparrow 110.5 \%\end{array}$ \\
\hline \multicolumn{2}{|c|}{ Group 6 (Low dose bare IONPs + VOO) } & $\begin{array}{c}8.29 \pm 0.30^{\mathrm{e}} \\
\uparrow 19.5 \%\end{array}$ \\
\hline \multicolumn{2}{|c|}{ Group 7 (High dose bare IONPs + VOO) } & $\begin{array}{c}9.29 \pm 0.46^{d} \\
\uparrow 33.9 \%\end{array}$ \\
\hline \multicolumn{2}{|c|}{ Group 8 (Low dose PEG coated IONPs) } & $\begin{array}{c}9.17 \pm 0.40^{d} \\
\uparrow 32.1 \%\end{array}$ \\
\hline \multicolumn{2}{|c|}{ Group 9(High dose PEG coated IONPs) } & $\begin{array}{c}11.24 \pm 0.42^{c} \\
\uparrow 62 \%\end{array}$ \\
\hline \multicolumn{2}{|c|}{ Group 10 (Low dose PEG coated IONPs + VOO) } & $\begin{array}{c}7.46 \pm 0.24^{\mathrm{f}} \\
\uparrow 7.5 \%\end{array}$ \\
\hline \multicolumn{2}{|c|}{ Group 11(High dose PEG coated IONPs + VOO) } & $\begin{array}{c}7.01 \pm 0.12 \mathrm{~g} \\
\uparrow 1 \%\end{array}$ \\
\hline \multirow{2}{*}{ One way ANOVA } & $\mathbf{F}$ & 400.609 \\
\hline & P value & $<0.001$ \\
\hline
\end{tabular}

PEG= polyethylene glycol; VOO= virgin olive oil; IONPs= iron oxide nanoparticles; $\mathrm{n}=$ number; S.D.= standard deviation; $\%=\%$ change from Control group; LSD= least significant difference. Means with different superscript letters are significantly different at $\mathrm{p}<0.05$, whereas means with the same superscript letters are non-significantly different in the same column.

\section{3) Antioxidant markers (\% of inhibition of superoxide dismutase and catalase):}

There was a statistically significant increase $(p \leq 0.05)$ in the inhibition percentage of superoxide dismutase and significant decrease $(\mathrm{p} \leq 0.05)$ in catalase activity in all IONPs treated groups compared to control group in a dose dependent manner, with improvement in PEG coated IONPs treated groups than bare IONPs treated groups. However, Co-administration of VOO showed more improvement $(p<0.05)$ in serum levels of antioxidant markers (Table 3). 
Table (3): The effect of sub chronic toxicity of bare and PEG coated iron oxide nanoparticles on antioxidant markers in adult male albino rats and the possible protection by virgin olive oil on the studied groups

\begin{tabular}{|c|c|c|c|}
\hline \multirow{2}{*}{\multicolumn{2}{|c|}{$\begin{array}{c}\text { Groups } \\
\mathrm{n}=7 \text { rats/group }\end{array}$}} & \begin{tabular}{|c|} 
Inhibition percentage of \\
superoxide dismutase $(\mathrm{IU} / \mathrm{I})$
\end{tabular} & $\begin{array}{c}\text { Catalase activity } \\
\text { (IU//) }\end{array}$ \\
\hline & & Mean \pm SD & Mean \pm SD \\
\hline \multicolumn{2}{|l|}{ Group 1 (Control) } & $21.37 \pm 0.90^{j}$ & $802.79 \pm 10.74^{\mathrm{ab}}$ \\
\hline \multicolumn{2}{|l|}{ Group 2 (PEG) } & $22.51 \pm 0.85^{i}$ & $792.02 \pm 15.98^{b}$ \\
\hline \multicolumn{2}{|l|}{ Group 3(VOO) } & $20.25 \pm 0.46^{k}$ & $814.12 \pm 10.98^{a}$ \\
\hline \multicolumn{2}{|c|}{ Group 4 (Low dose bare IONPs) } & $\begin{array}{c}42.92 \pm 0.87^{b} \\
\uparrow 100.9 \%\end{array}$ & $\begin{array}{c}573.25 \pm 14.39^{h} \\
\downarrow 28.6 \%\end{array}$ \\
\hline \multicolumn{2}{|c|}{ Group 5 (High dose bare IONPs) } & $\begin{array}{c}52.25 \pm 1.37^{\mathrm{a}} \\
\uparrow 144.5 \%\end{array}$ & $\begin{array}{c}482.52 \pm 16.93^{\mathrm{i}} \\
\downarrow 39.9 \%\end{array}$ \\
\hline \multicolumn{2}{|c|}{ Group 6 (Low dose bare IONPs + VOO) } & $\begin{array}{c}30.06 \pm 0.84^{f} \\
\uparrow 40.7 \%\end{array}$ & $\begin{array}{c}690.35 \pm 11.19^{\mathrm{e}} \\
\downarrow 14 \%\end{array}$ \\
\hline \multicolumn{2}{|c|}{ Group 7 (High dose bare IONPs + VOO) } & $\begin{array}{c}34.58 \pm 0.68{ }^{d} \\
\uparrow 61.8 \%\end{array}$ & $\begin{array}{c}628.77 \pm 13.65^{\mathrm{f}} \\
\downarrow 21.7 \%\end{array}$ \\
\hline \multicolumn{2}{|c|}{ Group 8 (Low dose PEG coated IONPs) } & $\begin{array}{c}32.85 \pm 0.811^{\mathrm{e}} \\
\uparrow 53.7 \%\end{array}$ & $\begin{array}{c}638.23 \pm 8.90^{f} \\
\downarrow 20.5 \%\end{array}$ \\
\hline \multicolumn{2}{|c|}{ Group 9 (High dose PEG coated IONPs) } & $\begin{array}{c}40.94 \pm 0.85^{c} \\
\uparrow 91.6 \%\end{array}$ & $\begin{array}{c}595.34 \pm 10.14^{\mathrm{g}} \\
\downarrow 25.9 \%\end{array}$ \\
\hline \multicolumn{2}{|c|}{ Group 10 (Low dose PEG coated IONPs + VOO) } & $\begin{array}{c}24.44 \pm 0.61^{\mathrm{h}} \\
\uparrow 14.4 \%\end{array}$ & $\begin{array}{c}774.07 \pm 11.77^{\mathrm{c}} \\
\downarrow 3.6 \%\end{array}$ \\
\hline \multicolumn{2}{|c|}{ Group 11(High dose PEG coated IONPs + VOO) } & $\begin{array}{c}28.93 \pm 0.91^{\mathrm{g}} \\
\uparrow 35.4 \%\end{array}$ & $\begin{array}{c}739.09 \pm 10.93^{\mathrm{d}} \\
\downarrow 7.9 \%\end{array}$ \\
\hline \multirow{2}{*}{ One way ANOVA } & $\mathbf{F}$ & 968.381 & 531.205 \\
\hline & P value & $<0.001$ & $<0.001$ \\
\hline post hoc test & LSD & 0.914 & $\mathbf{1 3 . 4 2 1}$ \\
\hline
\end{tabular}

PEG= polyethylene glycol; VOO= virgin olive oil; IONPs= iron oxide nanoparticles; $\mathrm{n}=$ number; S.D.= standard deviation; $\%=\%$ change from Control group; LSD= least significant difference. Means with different superscript letters are significantly different at $\mathrm{p}<0.05$, whereas means with the same superscript letters are non-significantly different in the same column.

\section{III: Histopathological results:}

Light microscopic examination of the liver tissues in group 1 (control), group 2 (PEG) and group 3 (VOO) showed normal histological structure, with hepatic cords radiating from the central vein forming anastomosing plates separated by blood sinusoids. Hepatocytes were polyhedral with eosinophilic cytoplasm having central rounded and vesicular nuclei. The portal tract area can be seen (Photomicrograph 1).

Light microscopic examination of the liver tissues in the group 4 (low dose bare IONPs) showed histological structure similar to that in the control group but there is mononuclear cellular infiltration (Photomicrograph 2). While the liver tissues in the group 5 (high dose bare IONPs) showed most of the hepatocytes are vacuolated with central rounded darkly stained nuclei. The central vein is congested; there is dilated and congested blood vessel in the portal tract area. Also, mononuclear cellular infiltration can be seen (Photomicrograph 3, 4).

Light microscopic examination of the liver tissues in the group 6 (low dose bare IONPs + VOO) showed histological structure similar to that of the control group but the sinusoids appear dilated (Photomicrograph 5). While the liver tissues in the group 7 (high dose bare IONPs + VOO) showed histological structure similar to that of the control group but the sinusoids appear dilated and congested. Also, in the portal tract area there is little mononuclear cellular infiltration and congested blood vessel (Photomicrograph 6).

Light microscopic examination of the liver tissues in the group 8 (low dose PEG coated IONPs) showed mononuclear cellular infiltration (Photomicrograph 7). While the liver tissues in the group 9 (high dose PEG coated IONPs) showed most of the hepatocytes are vacuolated with central rounded darkly stained nuclei. There is mononuclear cellular infiltration in portal tract area (Photomicrograph 8).

Light microscopic examination of the liver tissues in the group 10 (low dose PEG coated IONPs + VOO) and group 11 (high dose PEG coated IONPs + VOO) showed histological structure similar to that of the control group but the sinusoids appear dilated and congested (Photomicrograph 9). 


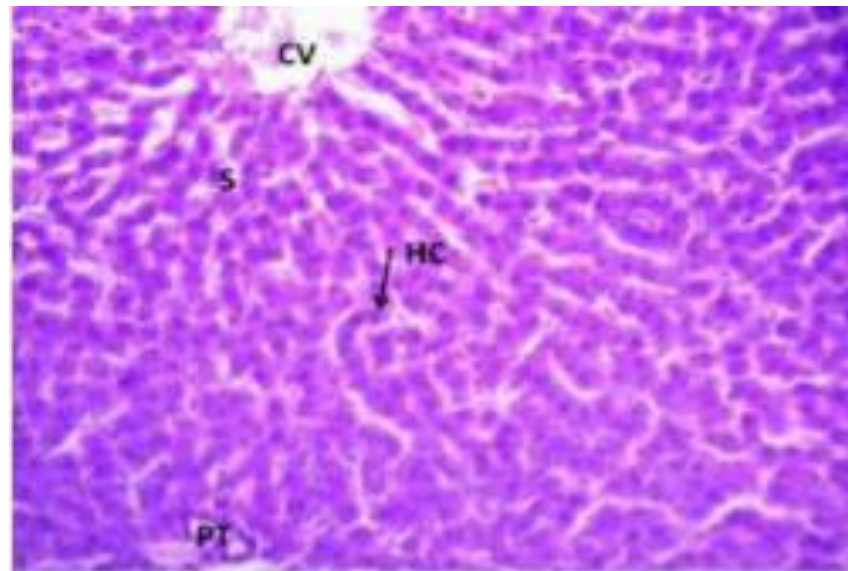

Photomicrograph (1): of a liver section of an adult male albino rat of control, PEG and VOO groups, showing that the liver tissue has normal histological structure with hepatic cords $(\mathrm{HC})$ radiating from the central vein $(\mathrm{CV})$ forming anastomosing plates separated by blood sinusoids (S). Hepatocytes are polyhedral with eosinophilic cytoplasm having central rounded and vesicular nuclei (arrow). The portal tract area (PT) can be seen (H\&E X 200).

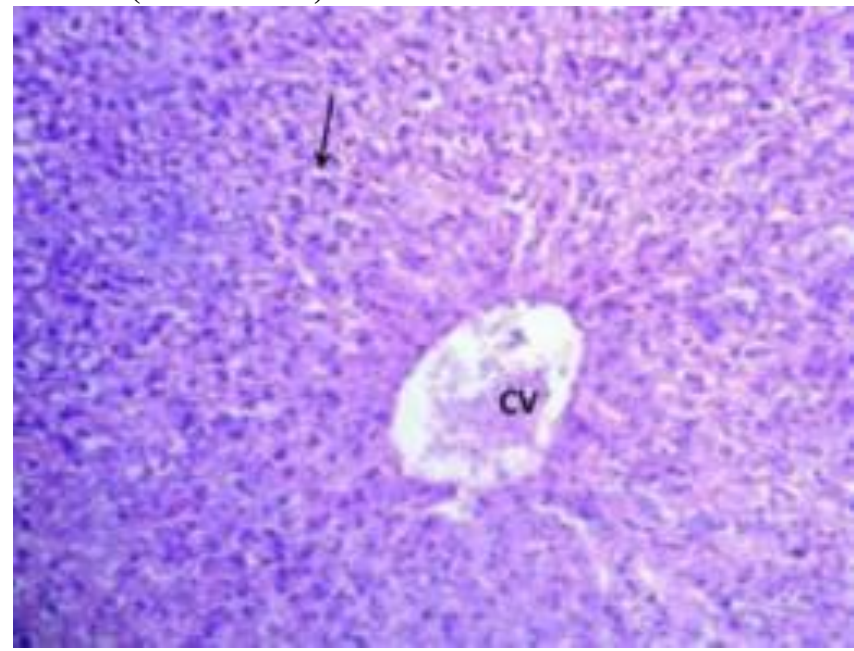

Photomicrograph (3): of a liver section of an adult male albino rat of high dose bare IONPs treated group, showing that most of the hepatocytes are vacuolated with central rounded darkly stained nuclei (arrow). The central vein $(C V)$ is congested (H\&E X 200).

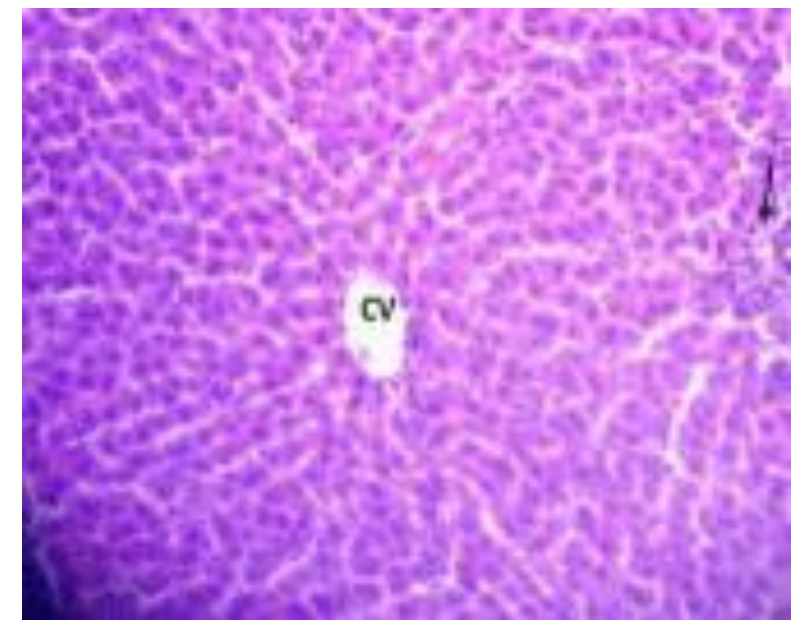

Photomicrograph of a liver section of an adult male albino rat of low dose bare IONPs treated group, showing there is mononuclear cellular infiltration (arrow) (H\&E X 200).

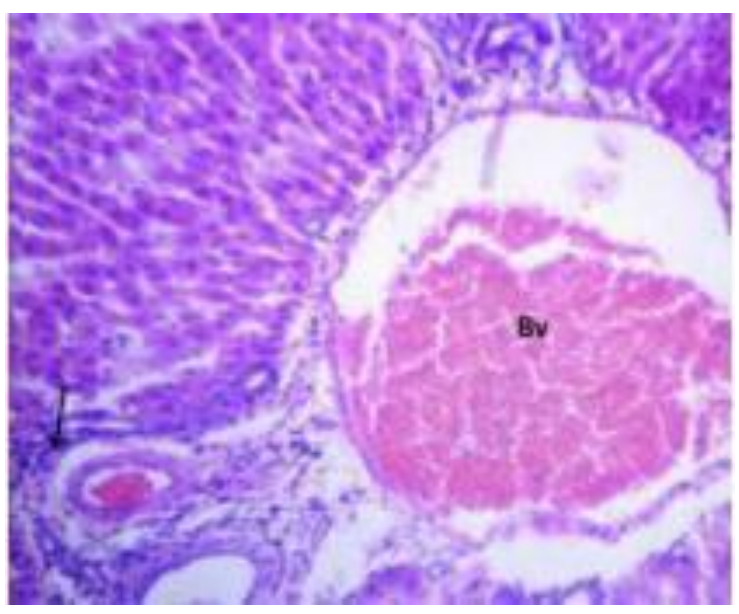

Photomicrograph (4) of a liver section of an adult male albino rat of high dose bare IONPs treated group, showing the portal tract area in which there is dilated and congested blood vessel (Bv). Also, mononuclear cellular infiltration (arrow) can be seen. (H\&E X 200). 


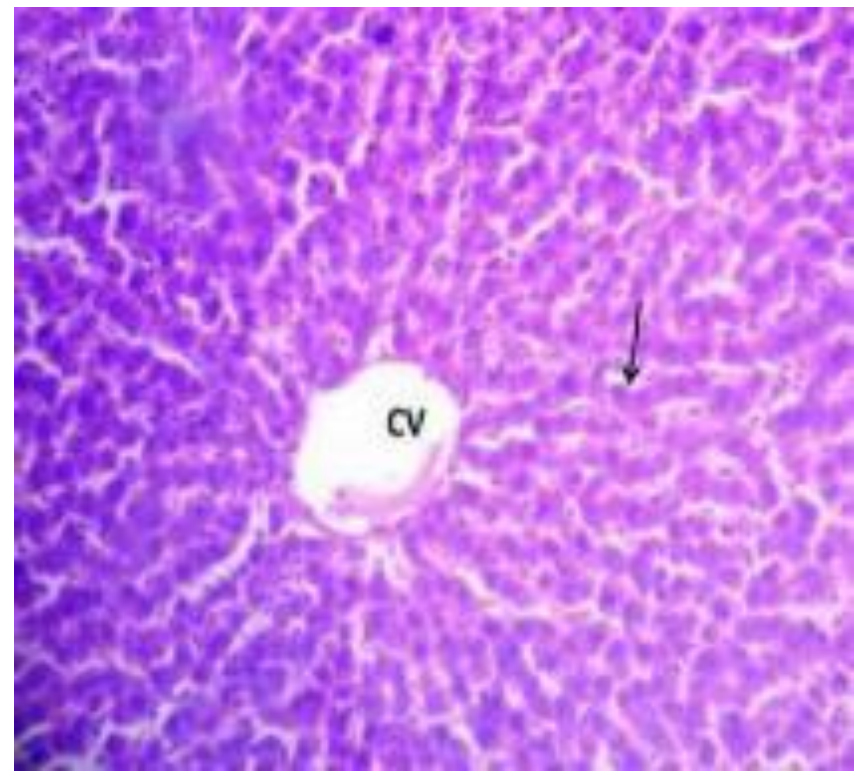

Photomicrograph (5): of a liver section of an adult male albino rat of low dose bare IONPs + VOO treated group, showing that the liver tissue has histological structure similar to that of the control group but the sinusoids (arrow) appear dilated. (H\&E X 200).

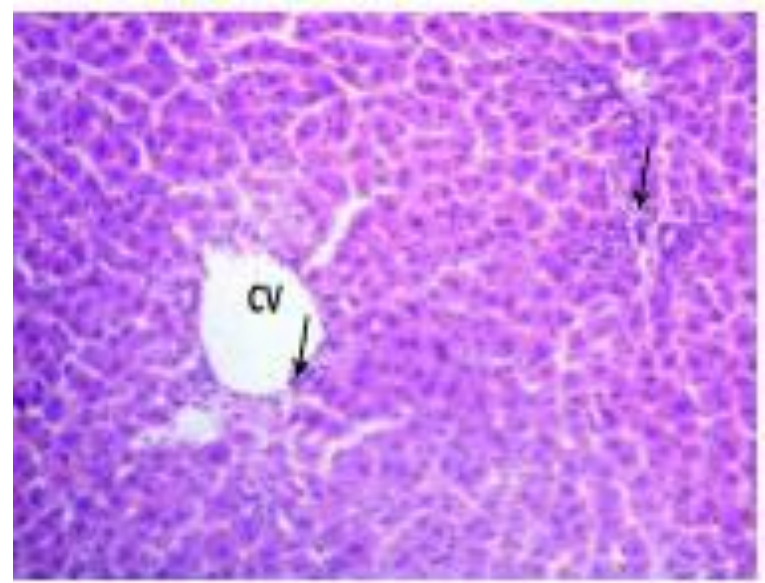

Photomicrograph (7): of a liver section of an adult male albino rat of low dose PEG coated IONPs treated group, showing that there is mononuclear cellular infiltration (arrows) (H\&E X 200).

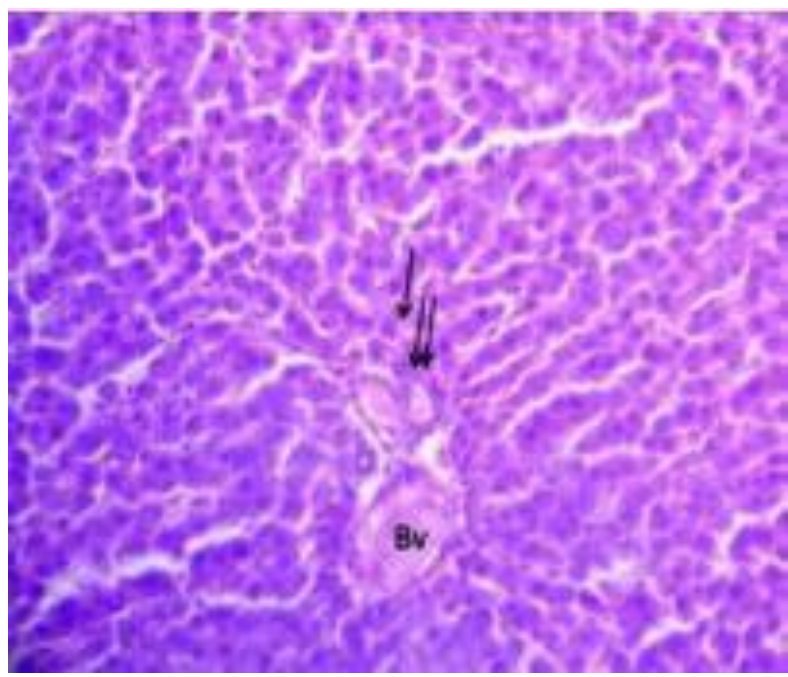

Photomicrograph (6): of a liver section of an adult male albino rat of high dose bare IONPs + VOO treated group, showing that the liver tissue has histological structure similar to that of the control group but the sinusoids (arrow) appear dilated and congested. Also, in the portal tract area there is little mononuclear cellular infiltration (double arrows) and congested blood vessel (Bv) (H\&E X 200).

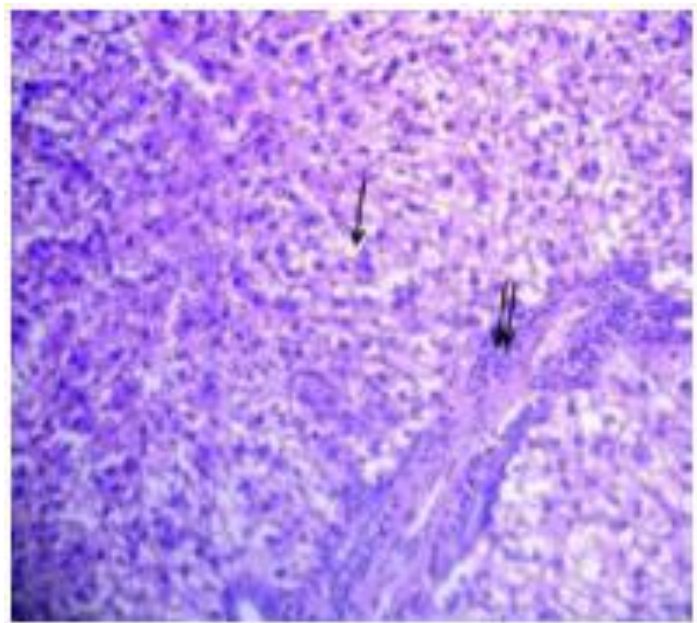

Photomicrograph (8): of a liver section of an adult male albino rat of high dose PEG coated IONPs treated group, showing that most of the hepatocytes are vacuolated with central rounded darkly stained nuclei (arrow). There is mononuclear cellular infiltration (double arrows) in portal tract area (H\&E X 200). 


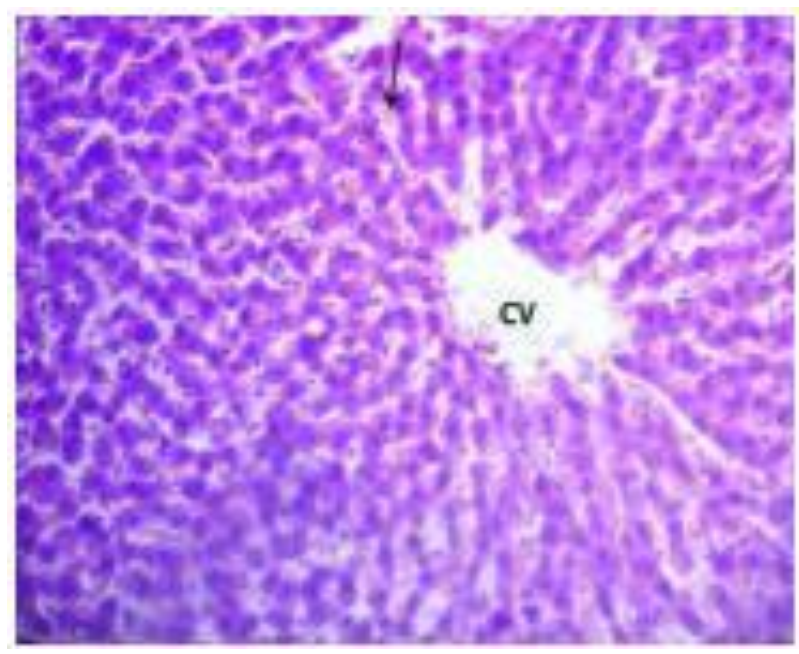

Photomicrograph (9): of a liver section of an adult male albino rat of low and high dose PEG coated IONPs + VOO treated group, showing that the liver tissue has histological structure similar to that of the control group but the sinusoids (arrow) appear dilated and congested (H\&E X 200).

\section{DISCUSSION}

In recent years, more and more nano medicines have been already approved by the U.S. Food and Drug Administration (FDA) for human use, and some others are undergoing clinical trials ${ }^{(19)}$. In the present study, we investigated the toxic effects of bare and PEG coated IONPS on the liver of rats and the protective effect of VOO on bare and PEG coated IONPS toxicity in adult male Albino rats.

The results of the current study as regard liver function markers revealed that oral administration of low and high doses of bare and PEG coated IONPs daily for 4 weeks to male albino rats resulted in significant increase $(\mathrm{p} \leq 0.05)$ in the serum levels of AST, ALT, ALP and total bilirubin and significant decrease $(p \leq 0.05)$ in the serum levels of total proteins in all IONPs treated groups compared to control group in a dose dependent manner. With improvement in PEG coated IONPs treated groups than bare IONPs treated groups.

The results of the present study were in agreement with those of El-Sayed $\boldsymbol{e t}$ al. ${ }^{(20)}$ as they observed significant increase in serum levels of AST, ALT, total and direct bilirubin, while serum level of albumin were significantly decreased in oral administrations of $(150 \mathrm{mg} / \mathrm{kg}$ b.wt.) for 30 days of IONPs-treated rats comparing to the normal control group.

The impairment of liver function by IONPs explained by Babadi et al. ${ }^{(21)}$ who observed that IONPs accumulate in the liver cells and lead to oxidative stress with generation of reactive oxygen species (ROS) causing hepatocyte injury. Damaged liver cells develop leaky membranes, allowing for escape of intracellular enzymes into the circulation, thereby raising their levels in the blood.

The improvement of liver function in PEG coated IONPs treated groups than bare IONPs treated groups might be explained by Abakumov et al. ${ }^{(22)}$ who stated that the protective action of PEG coating, which prevents active IONPs uptake and delays their degradation with the release of $\mathrm{Fe}^{3+} / \mathrm{Fe}^{2+}$ ions.

In the present study, Co-administration of VOO showed more improvement $(\mathrm{p}<0.05)$ in all liver function markers.

The result of the current study were in agreement with those of Mohammadian et al. ${ }^{(23)}$ who stated that administration of VOO for 30 days significantly decreases levels of serum ALP, AST, ALP in arsenic treated mice.

Also, the results of the present study were similar to those of Al-Seeni et al. ${ }^{(24)}$ who observed that rats injected with carbon tetrachloride $\left(\mathrm{CCl}_{4}\right)$ and cotreated daily with olive oil for 4 weeks orally using a stomach tube significantly $(\mathrm{P}<0.001)$ decreased the mean values of liver enzymes (ALT, AST, ALP and total bilirubin) and increased total protein, albumin compared with that of the negative control.

This improvement could be explained by Bulotta et al. (25) who stated that VOO contains phenolic compounds in general, and oleuropein (OL) derivatives in particular, act as natural antioxidants. Oleuropein and hydroxytyrosol behave as antioxidant acting as: a. free radical scavengers and radical chain breaking; b. anti-oxygen radicals; c. metal chelators.

The results of the present study as regard oxidative stress marker (MDA) showed that, oral administration of low and high doses of bare and PEG coated IONPs daily for 4 weeks to male albino rats resulted in a significant increase $(p \leq 0.05)$ in serum levels of MDA in all IONPs treated groups compared to control group in a dose dependent manner, with improvement in PEG coated IONPs treated groups than bare IONPs treated groups.

The result of the current study were in agreement with those of Rajan et al. (26) who observed a significant increase in the serum and liver MDA levels at a dose of $10 \mathrm{mg} / \mathrm{kg}$ b.wt. PEG-IONPs intravenously injected twice a week for the period of 30 days.

In the present study the increase in the serum MDA level explained by Ghorbel $\boldsymbol{e t}$ al. ${ }^{(\mathbf{5})}$ who attributed that to induction of oxidative stress by IONPs through overproduction of free radicals and disruption of the endogenous antioxidant system, subsequently, this oxidative stress-induced damage causes lipid peroxidation to cell membrane.

The improvement in PEG coated groups as regard MDA level explained by Griffete $\boldsymbol{e t}$ al. ${ }^{(27)}$ who stated that PEG is able to act as a limiting factor towards any potentially adverse effects that could be elucidated by 
IONPs. Polyethylene glycol creates a 'repulsive barrier' between a nano material and a biological system inhibiting possible toxic effects, by preventing dissolution and release of toxic ions.

These results were supported by Pumera, (28) who verified that polymer-coated iron oxide nanoparticles are non-toxic whereas uncoated $\mathrm{Fe}_{3} \mathrm{O}_{4}$ nanoparticles can catalyze to generate oxygen radicals.

In the current study, Co-administration of VOO showed more improvement $(\mathrm{p}<0.05)$ in serum levels of MDA.

These findings were in agreement with those of Wani et al. ${ }^{\left({ }^{(6)}\right.}$ who observed that co-administration of VOO with cadmium (Cd) ameliorated the toxic effect of $\mathrm{Cd}$ and reduced MDA level.

The improvement in MDA level by co-administration of VOO in this study explained by Ghorbel et al. ${ }^{(5)}$ who stated that virgin olive oil increases the resistance to lipid peroxidation and the antioxidant defense system because of its high content of phenolic compounds which can interact with biological systems acting as bioactive molecules inhibiting lipid peroxidation.

The results of the present study as regard antioxidant markers revealed that, oral administration of low and high doses of bare and PEG coated IONPs daily for 4 weeks to male albino rats resulted in significant increase $(p \leq 0.05)$ in the inhibition percentage of superoxide dismutase and significant decrease $(\mathrm{p} \leq 0.05)$ in catalase activity in all IONPs treated groups compared to control group in a dose dependent manner, with improvement in PEG coated IONPs treated groups than bare IONPs treated groups.

The findings of the current study were in line with those of Gaharwar and Paulraj ${ }^{(2)}$ who revealed that SOD and CAT activity was significantly decreased $(p<0.05)$ in a time and dose dependent manner.

This might probably be due to the heavy influx of superoxide radicals that in turn resulted in high levels of $\mathrm{H}_{2} \mathrm{O}_{2}$ generation, which subsequently inhibited SOD and CAT activity ${ }^{(29) .}$

The results of the present study were in accordance with the result of Radu et al. ${ }^{\left({ }^{(3)}\right)}$ who showed a significant decrease of CAT and SOD levels in treated groups vs. controls following the intravenous injection of polymeric coated IONPs-PM ( 5 and $15 \mathrm{mg}$ $\mathrm{Fe} / \mathrm{kg}$ b.wt.) during 14 days of exposure.

In the present study, Co-administration of VOO showed more improvement $(\mathrm{p}<0.05)$ in serum levels of antioxidant markers.

The results of the current study were in agreement with those of Mohammed et al. ${ }^{(31)}$ who showed a marked significant decrease $(P<0.05)$ in SOD and CAT in the VOO Cd treated group compared with control group. VOO nearly returned these values toward the normal.
The higher improvement in the antioxidant markers by concomitant administration of VOO in the present study could be explained by Allouche $\boldsymbol{e t}$ al. ${ }^{(32)}$ who stated that olive oil by its richness in carotenoids, tocopherols, vitamin E and polyphenols have a potential antioxidants properties acting as ROS scavenger as well as increasing the activity of antioxidant enzymes.

The results of the current study as regard histopathological changes in hepatic tissue in different studied groups showed that, oral administration of low and high doses of bare and PEG coated IONPs daily for 4 weeks to male albino rats resulted in remarkable histopathological changes in the liver of all IONPs treated groups in a dose dependent manner in the form of the hepatocytes are vacuolated with central rounded darkly stained nuclei, congestion of the central vein, congestion and dilatation of blood vessel in the portal tract area and mononuclear cellular infiltration. No difference was found between PEG coated IONPs treated groups and bare IONPs treated groups.

The results of the present study were in agreement with those of El-Sayed $\boldsymbol{e t}$ al. ${ }^{(20)}$ as they observed that liver of IONPs treated group demonstrated hydropic degeneration with congestion of the central vein, apoptosis/necrosis of hepatocytes, marked by pyknotic nuclei, severe vacuolation with infiltration of mononuclear inflammatory cells in the portal area. This may be due to the formation of highly reactive radicals and subsequent lipid peroxidation resulting from IONPs. Similarly Li et al. ${ }^{\left({ }^{33)}\right.}$ stated that hepatic lobule structures were unclear, and the hepatocytes were arranged irregularly. Focal hepatic necrosis was visible throughout the liver with a large amount of inflammatory cell infiltration, indicating that administration of $\mathrm{Fe}_{3} \mathrm{O}_{4}$-based nanoparticles by intravenous injection would cause serious hepatotoxicity.

The results of the current study could be explained by Attaran et al. ${ }^{(34)}$ who stated that hepatic accumulation of iron oxide nanoparticles affects the liver function. Also, stem cells and fibroblast cells were affected with decreasing of mitochondrial activity which leads to the morphological changes.

In the present study, Co-administration of VOO showed improvement in the hepatic histopathological damages.

The results of the present study were in agreement with those of Al-Seeni et al. (24) who recorded that liver tissue of olive oil treated group showed improvement of the degeneration effect of $\mathrm{CCl}_{4}$ with minimal inflammatory infiltration, due to their higher content of antioxidant substance such as flavonoids and phenolic compounds.

\section{Conclusion:}


Considering the results obtained from the present study it can be concluded that, both bare and PEG coated IONPs cause hepatotoxicity as revealed by the elevation of liver function parameters, induction of oxidative stress and the adverse histopathological changes in the liver tissues of rats. PEG coated IONPs were less toxic in comparison with bare IONPs. Treating the hepatotoxic rats with olive oil protected the liver structure against both IONPs toxicity. This hepatoprotective activity may be attributed to the biologically active compounds exist in olive oil which work to scavenge free radicals.

\section{RECOMMENDATION}

- More investigations and assessments are needed to assure the lower toxicity of PEGylated IONPs in biomedical utilization.

- Since virgin olive oil has potent antioxidants effect and hepatoprotective activity, it could be advisable to enrich our diet with it.

\section{REFERENCES}

1. Sukhanova A, Bozrova S, Sokolov P, Berestovoy M, Karaulov A (2018): Dependence of Nanoparticle Toxicity on Their Physical and Chemical Properties. Nanoscale Research Letters, 13:44- 65.

2. Gaharwar US and Paulraj R (2015): Iron Oxide Nanoparticles Induced Oxidative Damage in Peripheral Blood Cells of Rat. J. Biomedical Science and Engineering, 8: 274-286.

3. Arami H, Khandhar A, Liggitt D, Krishnan KM (2015): In vivo delivery, pharmacokinetics, biodistribution and toxicity of iron oxide nanoparticles. Chemical Society Reviewers, 44(23): 8576-8607.

4. Halliwell B and Gutteridge JMC (2015): Free Radicals in Biology and Medicine, 5th ed.; Oxford University Press: Oxford, UK, Pp. 124-146.

5. Ghorbel I, Elwej A, Jamoussi K, Boudawara T, Kamoun NG, Zeghal N (2015): Potential protective effects of extra virgin olive oil on the hepatotoxicity induced by co-exposure of adult rats to acrylamide and aluminum. Food \& function, 6(4): 1126-1135.

6. Wani FA, Ibrahim MA, Moneim MM, Almaeen AR (2018): Cytoprotectant and Anti-Oxidant Effects of Olive Oil on Cadmium Induced Nephrotoxicity in Mice. Open Journal of Pathology, 8: 31-46.

7. Ding L, Liu Z, Aggrey MO, Li C, Chen J, Tong L (2015): Nanotoxicity: the Toxicity Research Progress of Metal and Metal-Containing Nanoparticles. MiniReviews in Medicinal Chemistry, 15 (0): 1-15.

8. Rowe RC, Sheskey P and Quinn M (2009): Handbook of pharmaceutical excipients. Libros DigitalesPharmaceutical Press, London, England, Pp. 521.

9. Necib Y, Bahi A, Zerizer S, Abdennour C, Boulakoud MS (2014): Protective effect of virgin olive oil (Olea europea L.) against oxidative damage induced by mercuric chloride in rat albinos Wistar. Journal of Stress Physiology \& Biochemistry, 10(1): 45-58.

10. Kumari M, Rajak S, Singh SP, Kumari SI, Kumar PU, Murty US, Rahman MF (2012): Repeated oral dose toxicity of iron oxide nanoparticles: biochemical and histopathological alterations in different tissues of rats. Journal of Nanoscience and Nanotechnology, 12(3): 2149-2159.

11. IFCC [International Federation of Clinical Chemistry] (1980a): IFCC Methods for the measurement of catalytic concentration of enzymes, Part 2 IFCC Method for Aspartate aminotransferase (AST) and Part 3 IFCC Method for Alanine Aminotransferase (ALT). J Clin Chem Clin Biochem., 18: 521-534.

12.Scandinavien Society (1974): The Committee on Enzymes of The Scandinavian Society for Clinical Chemistry and Clinical Physiology: Recommended Methods for the Determination of Four enzymes in blood. Scand. J Clin Lab Invest., 32: 29-35.

13. Walter $M$ and Gerade $H$ (1970): Determination of the "Total"bilirubin and its conjugated "Direct" fraction. Microchem J.,15:231-240.

14. Gomal AC, Bardawill CF, David MM (1949): Colorimetric method to determine total protein. J Biol Chem., 177:751-755.

15. Ohkawa H, Ohishi N, Yagi K (1979): Assay for lipid peroxides in animal tissues by thiobarbituric acid reaction. Anal Biochem., 95(2):351-8.

16. Nishikimi M, Roa N, Yogi K (1972): Measurement of superoxide dismutase. Biochem Biophys Res Common., 46:849-54.

17. Aebi H (1984): A catalase in vitro in Methods. Enzymol., 105:121-6.

18. Bancroft JD and Gamble M (2002): Theory and practice of Histological Techniques. Fifth ed, Churchill Livingstone, London; Pp: 109-36.

19. Bobo D, Robinson K.J, Islam J, Thurecht KJ, Corrie SR (2016): Nanoparticle-based medicines: a review of FDA-approved materials and clinical trials to date. $\mathbf{J}$ of Pharmaceutical Research, 33 (10): 2373-2387.

20.El-Sayeda AA, Hussein MM, Solimana AH (2018): Naringenin and hesperidin ameliorate iron oxide nanoparticles toxicity in rat liver. Arabian Journal of Medical Sciences, 1(1): 26-30.

21. Babadi VY, Najafi L, Najafi A, Gholami H, Zarji MEP, Golzadeh J, Amraie E, Shirband A (2013): Evaluation of iron oxide nanoparticles effects on tissue and enzymes of liver in rats. Elixir International Journal Applied Chemistry, 55:13226-13229.

22. Abakumov MA, Semkina AS, Skorikov AS, Vishnevskiy DA, Ivanova AV, Mironova E, Chekhonin VP (2018): Toxicity of iron oxide nanoparticles: Size and coating effects. Journal of Biochemical and Molecular Toxicology, 32(12): 222-25.

23. Mohammadian M, Mianabadi M, Zargari $M$, Karimpour A, Khalafi M, Amiri FT (2018): Effects of olive oil supplementation on sodium arsenate-induced hepatotoxicity in mice. International Journal of Preventive Medicine, 9:59-63.

24. Al-Seeni MN, El Rabey HA, Zamzami MA, Alnefayee AM (2016): The hepatoprotective activity of olive oil and Nigella sativa oil against $\mathrm{CCl}_{4}$ induced hepatotoxicity in male rats. BMC Complementary and Alternative Medicine, 16(1): 438-451.

25. Bulotta S, Celano M, Lepore SM, Montalcini T, Pujia A, Russo D (2014): Beneficial effects of the olive oil 
phenolic components oleuropein and hydroxytyrosol: focus on protection against cardiovascular and metabolic diseases. Journal of Translational Medicine, 12(1): 219228.

26. Rajan B, Sathish S, Balakumar S, Devaki T (2015): Synthesis and dose interval dependent hepatotoxicity evaluation of intravenously administered polyethylene glycol-8000 coated ultra-small superparamagnetic iron oxide nanoparticle on Wistar rats. Environmental Toxicology and Pharmacology, 39(2): 727-735.

27. Griffete N, Clift MJ, Lamouri A, Digigow RG, Mihut AM, Fink A, Dietsch H (2012): Amino covalent binding approach on iron oxide nanoparticle surface: toward biological applications. Colloids and Surfaces A. Physicochemical and Engineering Aspects, 415: 98-104.

28.Pumera M (2011): Nanotoxicology: the molecular science point of view. Chemistry-An Asian Journal, 6(2): 340-348.

29. Li JJ, Muralikrishnan S, Ng CT, Yung LY, Bay BH (2010): Nanoparticle-induced pulmonary toxicity. J Experimental Biology and Medicine, 235(9): 1025-1033.

30. Radu M, Din I, Hermenean A, Cinteza O, Burlacu R, Ardelean A, Dinischiotu A (2015): Exposure to iron oxide nanoparticles coated with phospholipid-based polymeric micelles induces biochemical and histopathological pulmonary changes in mice. International Journal of Molecular Sciences, 16(12): 29417-29435.

31. Mohammed ET, Hashem KS, Rheim MR (2014): Biochemical study on the impact of Nigella sativa and virgin olive oils on cadmium-induced nephrotoxicity and neurotoxicity in rats. American Journal of Physiology, Biochemistry and Pharmacology, 3(2): 71-78.

32. Allouche Y, Beltran G, Gaforio JJ, Uceda M, Mesa M (2010): Antioxidant and antiatherogenic activities of pentacyclic triterpenic diols and acids. $\mathbf{J}$ of Food and Chemical Toxicology, 48(10): 2885-2890.

33. Li J, Cha R, Zhang Y, Guo H, Long K, Gao P, Jiang X (2018): Iron oxide nanoparticles for targeted imaging of liver tumors with ultralow hepatotoxicity. Journal of Materials Chemistry B., 6(40): 6413-6423.

34. Attaran HR, Fatemi F, Rasooli A, Dadkhah A, Mohammadi Malayeri MR, Dini S (2018): Zataria multiflora Essential oil Prevent Iron Oxide Nanoparticlesinduced Liver Toxicity in Rat Model. Journal of Medicinal Plants and By-Product, 7(1): 15-24. 